\title{
Modelo do jogo de futsal e subsídios para o ensino
}

\author{
Rafael Batista Novaes* \\ Thiago André Rigon** \\ Luiz Eduardo Pinto Bastos Tourinho Dantas***
}

\begin{abstract}
Resumo: O presente estudo tem como objetivo propor um modelo do jogo de futsal visando auxiliar na estruturação de uma didática para a modalidade. A construção do modelo foi feita com base na experiência dos autores com a modalidade e na literatura específica. Optou-se por um recorte sistêmico do fenômeno com o intuito de superar a perspectiva tecnicista, em que a ação no jogo é vista como a justaposição de gestos técnicos, e realçar a importância da tomada de decisão.
\end{abstract}

Palavras-chave: Esportes. Ensino. Técnicas de apoio à decisão. Formação de conceito.

\section{INTRODUÇÃo}

O futsal é uma Modalidade Esportiva Coletiva (MEC) muito popular no Brasil, com forte presença nos currículos de Educação Física e nas "escolas" de esporte de uma maneira geral. Em função disso, as questões relativas à como ensiná-lo têm grande relevância.

Bayer (1986) define como MEC um conjunto de jogos que possuem as seguintes características comuns: um objeto (geralmente esférico) que pode ser lançado seja com as mãos, com os pés ou através de algum instrumento; um terreno de jogo delimitado em que se desenrola o jogo e limita a ação dos jogadores; um alvo/

\footnotetext{
*Universidade de São Paulo. Escola de Educação Física e Esporte. São Paulo, SP. Brasil. E-mail: batistaeefe@gmail.com

***Universidade de São Paulo. Escola de Educação Física e Esporte. São Paulo, SP. Brasil. E-mail: tarigon@uol.com.br

***Universidade de São Paulo. Escola de Educação Física e Esporte. São Paulo, SP Brasil. E-mail: Idantas@usp.br
} 
meta a atacar e outro a defender; companheiros que cooperam em função de um objetivo comum; adversários que estabelecem relações de oposição; e as regras que regulamentam a maneira de jogar proibindo ou autorizando ações.

$\mathrm{Na}$ literatura de ensino das MECs, propostas que consideram o jogo sob uma perspectiva sistêmica têm se constituído como hegemônicas. Nessa perspectiva, o jogo extrapola a simples justaposição de gestos técnicos e sua dinâmica emerge das relações dos elementos que o compõem. A complexidade dessas relações proporciona grande variabilidade de acontecimentos e exige que os jogadores tomem decisões continuamente, na maioria das vezes, sob forte pressão temporal. Por isso, o processo pedagógico deve priorizar exercícios em que os alunos sejam incentivados a tomarem decisões e a refletirem sobre os problemas do jogo, indo além da simples repetição de gestos técnicos desprovida de contexto (GARGANTA; GREHAIGNE, 1999).

Apesar da consolidação dessas propostas, ainda são grandes os desafios encontrados pelos treinadores para organização de programas de ensino. Alguns autores advogam que a construção de um modelo visando apreender a dinâmica do jogo auxiliaria na derivação de instrumentos de intervenção coerentes. Não se trataria de reduzi-lo a uma noção abstrata, mas de procurar identificar seus aspectos constituintes, que permitam um entendimento da sua dinâmica e orientem a estruturação de uma didática que forme jogadores adequados para sua natureza (GARGANTA; OLIVEIRA, 1996; GARGANTA, 2002). Assim, no presente ensaio, buscou-se criar um modelo do jogo de futsal com a finalidade principal de orientar a organização de programas de ensino.

A construção do modelo foi realizada a partir de questionamentos e discussões a respeito das ações de oposição e cooperação que caracterizam empiricamente o jogo, tendo como suporte a literatura de ensino (MAHLO, 1974; BAYER, 1979; BUNKER; THORPE, 1982; GARGANTA; OLIVEIRA, 1996; GREHAIGNE; GODBOUT; BOUTHIER, 1997; HERNANDÉZ

Movimento, Porto Alegre, v. 20, n. 3, p. 1039-1060, jul./set. de 2014. 
MORENO, 1998; GREHAIGNE; GODBOUT; BOUTHIER, 1999; GARGANTA, 2002 GRAÇA; RICARDO; PINTO, 2006; GRECO; 2007), modelos de outros jogos coletivos (GARGANTA; GREHAIGNE, 1999; SEABRA, 2010; LAMAS, 2012) e a experiência dos autores com a modalidade. Os dois primeiros autores deste ensaio são treinadores de equipes de futsal escolares e universitárias da região da Grande São Paulo com mais de dez anos de experiência nas mais diversas faixas etárias (crianças, adolescentes e adultos). Além disso, possuem mais de vinte anos de experiência como jogadores de competições amadoras.

Inicialmente, são apresentadas característcas gerais do futsal. Em seguida, é apresentado um modelo do jogo com a finalidade não apenas de representar o jogo, mas de subsidiar a sua sistematização para fins didáticos. Com base nesse modelo, são propostas heurísticas (estruturas genéricas para soluções dos problemas enfrentados durante o jogo de futsal) para orientar o ensino.

\section{Modelo do JOGO DE FUtSAL: CARACTERÍSTICAS GERAIS}

O futsal é uma MEC de invasão, pois não há barreira que impeça o deslocamento das equipes ao campo adversário, o que permite livre ocupação dos espaços. Além de ser de invasão, é uma MEC de participação simultânea, pois o implemento de jogo permanece em disputa direta (HERNANDÉZ MORENO, 1998).

No futsal, é possível discriminar dois níveis de organização principais: o jogo, identificado pelo confronto global entre duas equipes e a equipe, formados a partir das relações de cooperação estabelecida entre os jogadores. $\mathrm{O}$ confronto global entre as equipes pode ser dividido em outros dois subníveis: os confrontos parciais, identificados pela relação de cooperação e oposição estabelecidas entre grupos de jogadores (dois ou mais) em determinadas situações e zonas do jogo; e os confrontos elementares, isto é, a relação de cooperação e oposição sob o ponto de vista de um indivíduo. (GARGANTA; GREHAIGNE, 1999). Do ponto de vista da equipe,

Movimento, Porto Alegre, v. 20, n. 3, p. 1039-1060, jul./set. de 2014. 
dois principais subníveis de organização podem ser enunciados: grupo de jogadores, isto é, a relação estabelecida entre dois ou mais jogadores, e os jogadores.

A dinâmica do jogo (macrossistema) emerge da relação entre sua lógica interna, as regras e terreno que o regulamentam (estrutura) e a competência das equipes. A lógica interna consiste no confronto entre duas equipes que buscam coordenar suas ações com o intuito de movimentar a bola para a meta adversária e impedir que os adversários movimentem-na para a sua meta (GREHAIGNE; GODBOUT; BOUTHIER, 1997, 1999). As regras e o terreno de jogo estabelecem as condutas permitidas e os limites físicos. A competência das equipes, por sua vez, é representada pela coordenação das relações estabelecidas entre os jogadores para resolver os problemas que emergem no jogo. De uma maneira geral, pode-se enunciar duas principais categorias de problemas enfrentados pelas equipes: problemas relacionados à ocupação do espaço e problemas relacionados à organização (estratégicos).

Os problemas relacionados ao espaço podem ser ilustrados da seguinte maneira: para superar os adversários, a equipe deve coordenar as ações ofensivas, com o intuito de finalizar de maneira bem-sucedida; e defensivas, com o intuito de impedir a finalização adversária bem-sucedida. Para que consiga a finalização bemsucedida, a equipe deve criar e selecionar as oportunidades de finalização. Por outro lado, para impedir a finalização adversária bem-sucedida, deve impedir a criação de oportunidades para que ela ocorra. Para criar oportunidades de finalização, precisa-se criar espaço e progredir para zonas favoráveis à finalização. Por outro lado, para impedir a criação de oportunidades de finalização, precisa-se evitar a progressão adversária a zonas suscetíveis à finalização.

Os problemas relacionados à organização, por sua vez, podem ser assim descritos: para alcançar o objetivo do jogo (a vitória), as equipes (e os jogadores) enfrentam problemas organizacionais e agem estrategicamente, isto é, elaboram planos visando convergir 
as ações (aumentar a sincronia das ações) para aumentar a probabilidade de êxito. Para convergir as ações e aumentar a probabilidade de êxito, é preciso reduzir as incertezas nas relações entre os jogadores da própria equipe e aumentar a dúvida/conflito nas relações entre os jogadores da equipe adversária. Diante da relação de oposição estabelecida entre as equipes, uma equipe ao mesmo tempo em que busca convergir ou facilitar as ações de seus jogadores (cooperação), busca dificultar a ação dos jogadores adversários e da equipe adversária (oposição).

A complexidade dessas relações de cooperação e oposição faz comque jogo apresente uma alta imprevisibilidade. Os permanentes embates geram constantes modificações na configuração do jogo. Essas modificações representam perturbações à organização das equipes, levando à necessidade ininterrupta de atualizações com o intuito de gerenciar a desordem e preservar a coerência interna (SEABRA, 2010). Nesse sentido, as equipes (e os jogadores) envolvem-se continuamente na solução de problemas com intuito de se adaptar às condições ou modificá-las para concretizar seus objetivos.

As equipes buscam prescrever estratégias que possam coordenar o comportamento coletivo de forma a superar a organização adversária. Tais prescrições são possíveis, pois, apesar da alta imprevisibilidade dessa classe de fenômeno, os acontecimentos apresentam padrões que se repetem ao longo do tempo, sendo, portanto, passíveis de serem modelados. Partindo do princípio de que no jogo é possível identificar vários níveis de organização (ou subsistemas), tanto seria possível observar padrões mais gerais que dizem respeito à dinâmica de oposição entre as equipes (confronto global, confrontos parciais e elementares), quanto seria possível observar padrões mais específicos que dizem respeito à organização de cada equipe, ao comportamento de determinados grupos de jogadores e jogadores. Sendo assim, torna-se possível a construção de prescrições mais genéricas que atendam às demandas básicas de qualquer jogo e prescrições mais específicas às equipes, grupo de jogadores e jogadores particulares.

Movimento, Porto Alegre, v. 20, n. 3, p. 1039-1060, jul./set. de 2014. 
Como já apontamos anteriormente, pelo futsal se tratar de um jogo de invasão, com participação simultânea de ambas as equipes, as ações de cooperação/oposição e ataque/defesa estão o tempo todo presentes, configurando um embate incessante de duas forças inteiramente antagônicas que procuram, ao mesmo tempo, deslocar o implemento em direção à baliza adversária e afastá-lo de sua própria baliza. Nessa forma de entender o jogo, as noções de que a equipe com a posse de bola está no ataque e a equipe sem a posse está em defesa devem ser vistas com cautela. Isso quer dizer que, tanto com a posse de bola como sem a posse de bola, tanto os problemas de ordem ofensiva como defensiva estão o tempo todo presentes (GREHAIGNE, GODBOUT, BOUTHIER, 1997, 1999). Por exemplo, as equipes também defendem em situações com a posse de bola (com uma circulação de bola equilibrada, mantendo a posse da bola, etc.) e atacam em situações sem a posse de bola (induzindo a circulação adversária para um ponto favorável a sua equipe, marcando pressão e roubando a bola perto da meta adversária, etc.).

Com base nessa concepção do jogo, propõe-se que a ação coletiva de uma equipe de futsal pode ser dividida em duas fases principais: quando tem a posse de bola e quando não tem a posse de bola; e duas subfases: momento de transição com a recuperação da posse e momento de transição com a perda da posse de bola. As ações com bola representam a movimentação ativa da bola, enquanto que as sem a posse de bola representam a indução da ação de movimentação da bola dos adversários.

O que foi exposto acima, apesar de ter sido pensado para representar o jogo de futsal, pode ser também representativo para outras modalidades coletivas de invasão como o futebol, o basquetebol, o handebol, entre outros. Entretanto, o jogo de futsal apresenta algumas particularidades importantes de serem destacadas. Primeiro, não há uma regra que exerça pressão para finalização, como no basquete (24 segundos) ou no handebol (proibição de jogar sem intenção de atacar - "jogo passivo"). Tal característica acentua o potencial defensivo da posse da bola,

Movimento, Porto Alegre, v. 20, n. 3, p. 1039-1060, jul./set. de 2014. 
pois enquanto a posse da bola é mantida a outra equipe não pode pontuar. $\mathrm{O}$ fato de ser jogado predominantemente com os pés, sendo uma das bases de apoio ocupada para o controle da bola, dificulta o equilíbrio, a locomoção e o próprio controle da bola. Além disso, diferentemente do basquetebol ou do handebol, em que a bola pode ser agarrada, no futsal (e no futebol em suas diversas formas) ela nunca está sob controle absoluto do jogador (com exceção ao goleiro). Desse modo, o controle da bola geralmente demanda contínua perseguição visual e quanto mais o jogador opta por visualizá-la diretamente, mais seu campo visual fica limitado e terá sua leitura de jogo prejudicada. Por outro lado, quanto mais o jogador opta por levantar a cabeça e olhar para o terreno de jogo, mais difícil fica o controle da bola, além, é claro, mais exposto a um desarme. Quando comparado ao futebol de campo, no entanto, pode-se dizer que há uma menor dificuldade (e uma maior facilidade para realizar manobras no solo), pois o terreno de jogo é plano e regular e a bola quica menos e é menor.

As restrições proporcionadas por ser jogado com os pés, somadas à dimensão relativamente pequena do gol, também geram outra condição particular: a dificuldade de finalizar em posições favoráveis e concretizar o gol - embora, se for mais uma vez comparado ao futebol de campo, devido à dimensão menor do terreno de jogo, exista uma proporção maior de zonas suscetíveis à finalização bem-sucedida. Nesse sentido, não é incomum observar uma equipe sair derrotada mesmo conseguindo mais posse de bola e/ou um número maior de finalizações. Devido às dimensões reduzidas do terreno, o goleiro tem grande participação no jogo, tanto defendendo a meta das finalizações adversárias, quanto realizando assistências e finalizações. Este jogador é muitas vezes utilizado como um jogador de "linha" (goleiro-linha) para obtenção de vantagem numérica apesar de algumas restrições impostas pela regra. A utilização do goleiro-linha (entrada de um jogador de "quadra" em substituição do goleiro), ao mesmo tempo em que proporciona uma vantagem numérica para equipe com a posse de bola, representa uma situação de risco, pois a meta fica menos protegida.

Movimento, Porto Alegre, v. 20, n. 3, p. 1039-1060, jul./set. de 2014. 


\section{Modelo do jogo de fUtSAL: enfoque didÁtico}

Tomando por base oque foi apresentado acima, buscou-se realizar uma transposição didática do modelo do jogo de futsal e, ao mesmo tempo, propor heurísticas que orientariam o processo pedagógico. Em um primeiro momento, foram propostas heurísticas gerais, que auxiliariam na solução dos problemas de ordem organizacionais e espaciais defrontados durante todo o jogo. Em seguida, procurou-se enunciar heurísticas mais específicas às fases (ação da equipe com bola e sem bola), subfases (transições) e respectivas categorias de ação. É importante frisar que a posse dessas heurísticas, por si só, não é capaz de gerar ações eficientes, mas ela configura-se como uma forma geral de perceber e lidar com o problema, ou, em outras palavras, um quadro de referência para se pensar o que fazer no jogo.

\subsection{Problemas organizacionals}

Heurísticas: identificar padrões de ação com bola e sem bola; identificar pontos fortes e fracos; buscar superioridade; dissimular ações e intenções; responder coletivamente aos movimentos.

Para aumentar a probabilidade de êxito da equipe, a análise dos padrões de ação com bola e sem bola dos adversários e a identificação dos pontos fortes e fracos possibilitaria um delineamento estratégico mais efetivo. A superioridade numérica e as dissimulações das ações e intenções promoveriam redução das certezas por parte do adversário, o que facilitaria seu desequilíbrio.

Responder coletivamente aos movimentos implica em pensar e executar a ação individual dentro do plano coletivo, o que aumentaria a sincronia da equipe.

\subsection{Problemas espacials}

Heurísticas: criar linha de chute; conquistar um espaço efetivo; marcar e se desmarcar.

Movimento, Porto Alegre, v. 20, n. 3, p. 1039-1060, jul./set. de 2014. 
Para realizar um gol é necessário que haja uma finalização em direção à meta. Para que a finalização ocorra é preciso criar uma linha de chute (oportunidade favorável para finalizar). Como se trata de um jogo em que é preciso invadir o campo adversário para conseguir oportunidades de finalização e, ao mesmo tempo, é preciso impedir que os adversários invadam seu campo, a conquista de espaço é fundamental para que se tenha êxito. Para conquistar este espaço é preciso que se supere os adversários, isto é, que se marque, quando a equipe está sem a posse da bola, e se desvencilhe da marcação, quando a equipe tem a posse da bola.

\subsection{AçÕES DA EQUIPE COM A POSSE DE BOLA}

As ações da equipe com a posse da bola foram divididas em três categorias com base na sua complexidade (quantidade de interações entre jogadores da mesma equipe). Em um primeiro nível, estão as ações individuais, em segundo nível as ações grupais (dois ou mais jogadores) e em terceiro nível as ações coletivas (a equipe como um todo).

3.3.1 AçÕES INDIVIDUAIS DOS JOGADORES DA EQUIPE COM A POSSE DE BOLA

As ações individuais do jogador da equipe com a posse de bola foram subdivididas em: ações individuais com a posse de bola (portador da bola) ações individuais sem a posse de bola.

\subsubsection{AçÕES INDIVIDUAIS COM A POSSE DE BOLA}

As ações individuais com a posse de bola foram assim discriminadas:

a) Recepção/Domínio (coxa, pé, peito, sola, etc.): ação de controlar a bola quando esta é lançada por outro jogador;

Heurísticas: dominar em progressão quando possível; dominar

Movimento, Porto Alegre, v. 20, n. 3, p. 1039-1060, jul./set. de 2014. 
com a sola quando a bola for rasteira; amortecer a bola; analisar o espaço em volta antes de receber a bola.

Dominar em progressão representa uma ação em que o jogador domina a bola já a projetando para zonas mais favoráveis dificultando a ação do marcador.

O domínio com a sola geralmente facilita o controle quando a bola está se deslocando no solo, embora essa ação possa ser realizada efetivamente com outras partes do pé.

Amortecer a bola representa um movimento contra a trajetória da bola para reduzir sua velocidade, o que contribuiria para uma recepção efetiva.

Analisar o espaço em volta seria importante para o indivíduo que vai receber ou que já recebeu a bola ter consciência do que está acontecendo à sua volta.

b) Proteção: ação de proteger a bola do alcance dos adversários;

Heurísticas: utilizar o corpo (braço, ombro, quadril etc.) para proteger a bola; manter a bola em movimento.

Algumas partes do corpo como o braço, o ombro e o quadril podem ser utilizadas para dificultar que o adversário se aproxime da bola.

Manter a bola em movimento também dificultaria a ação do marcador e ajudaria na proteção da bola.

c) Passe (rasteiro, cavado, longo; com o lado do pé, com o peito do pé, de cabeça, etc.): ação de direcionar a bola a um companheiro de equipe.

Heurísticas: analisar o espaço (levantar a cabeça, analisar o espaço em volta); passar ao companheiro em melhores condições; equilibrar o corpo. 
Para aumentar a probabilidade de realizar um passe efetivo, isto é, passar para um companheiro em melhores condições, o jogador com a posse deveria analisar o espaço (levantar a cabeça e analisar o espaço em sua volta) e equilibrar o corpo no momento do passe. Para equilibrar o corpo, algumas dicas como colocar o pé de apoio ao lado da bola e movimentar o braço contralateral para estabilizar o movimento podem ajudar na ação.

d) Finalização: ação de impulsionar a bola em direção ao gol;

Heurísticas: olhar para meta e goleiro; equilibrar o corpo; tirar do goleiro e defensores.

Para aumentar a probabilidade de realizar uma finalização bem sucedida, algumas estratégias como olhar para a meta e buscar tirar do goleiro e dos defensores podem ajudar. Além disso, o equilíbrio do corpo na hora da finalização pode ser fundamental. Para tanto, algumas dicas como colocar o pé de apoio ao lado da bola, movimentar o braço contralateral para estabilizar o movimento e realizar contra-movimento da coxa e da perna para acertar a bola com mais potência podem ajudar na execução da ação.

e) Drible (condução): ação de progredir e de manobrar com a bola.

Heurísticas: levantar a cabeça; analisar o espaço; penetrar se tiver o espaço livre; mudar de direção e mudar de ritmo.

O jogador em ação de drible deveria levantar a cabeça e analisar o espaço em sua volta para ter maior consciência do que está acontecendo, pois, como a bola é conduzida no solo, há uma tendência de se olhar para baixo para o melhor controle.

Penetrar no espaço livre garantiria a posse da bola e uma marcação menos efetiva do adversário.

A mudança de direção e ritmo ajudaria para superação do adversário.

Movimento, Porto Alegre, v. 20, n. 3, p. 1039-1060, jul./set. de 2014. 
3.3.1.2 AçõES INDIVIDUAIS SEM A POSSE DE BOLA (DOS JOGADORES DA EQUIPE COM A POSSE DE BOLA)

As ações individuais sem a posse de bola (dos jogadores da equipe com a posse de bola) foram assim discriminadas:

a) Apoio ao portador da bola e à equipe: ação de se apresentar para dar apoio ao portador da bola e a equipe. Para apoiar o portador da bola e a equipe, os jogadores sem a posse de bola podem buscar dar opção de passe, abrir espaço para os companheiros e fazer o balanço defensivo.

Heurísticas: deslocar-se para um espaço vazio; procurar receber em uma posição mais favorável; mudar de direção; mudar de ritmo; fugir do campo visual do marcador; infiltrar se não houver pressão na bola e aproximar se houver pressão ao portador da bola.

Para criar uma opção de passe efetiva os jogadores devem procurar receber a bola em uma posição mais favorável à equipe. Para tanto, têm de fugir da marcação buscando se deslocar para um espaço vazio. Caso um adversário tente impedir a criação deste espaço acompanhando esse deslocamento, é preciso que o jogador busque ludibriá-lo. Para tanto, algumas estratégias como mudar de direção rapidamente, mudar o ritmo da corrida, fugir do campo visual do marcador, podem ser utilizadas. Os jogadores sem a posse de bola, além de buscarem criar opções para que possam receber a bola, podem buscar abrir espaço para os companheiros. Para tanto, podem atrair a marcação para um determinado setor da quadra, abrindo espaço em outros setores para ação de outros jogadores. Além de abrir espaço para os companheiros, os jogadores sem a posse de bola devem se preocupar com o balanço defensivo para manter a equipe equilibrada em caso de perda da posse. As heurísticas "infiltrar se não houver pressão na bola" e "aproximar se houver pressão na bola" ajudariam a guiar os movimentos dos jogadores sem a bola. Caso o portador da bola esteja sofrendo pressão e, portanto, com menor angulação para realizar um passe, seria mais efetivo que os jogadores sem a posse se aproximassem

Movimento, Porto Alegre, v. 20, n. 3, p. 1039-1060, jul./set. de 2014. 
para dar apoio. Caso o portador não esteja sofrendo pressão ele terá maior angulação para um passe. Assim, os jogadores sem a posse de bola teriam a possibilidade de invadir mais o território adversário e permanecer apoiando o jogador com a posse.

3.3.2 AçõES GRUPAIS DOS JOGADORES DA EQUIPE COM A POSSE DE BOLA

As ações grupais da equipe com a posse de bola foram assim discriminadas:

a) Tabela: troca de passes rápida entre dois jogadores. A passa para $\mathrm{B}$ que devolve a bola rapidamente para $\mathrm{A}$;

Heurísticas: aproximar-se do marcador para soltar a bola.

Se o portador da bola se aproximar do marcador antes de passar a bola, ele terá menos espaço para correr e será mais fácil tomar a frente para receber o segundo passe.

b) Triangulação: troca de passes rápida entre três jogadores. A passa para $\mathrm{B}$ que rapidamente passa para $\mathrm{C}$;

Heurísticas: antecipar o segundo passe.

A antecipação do jogador $\mathrm{C}$ para receber o segundo passe seria fundamental para realização da triangulação.

c) Corta-luz: ação de passe ou finalização sem que haja o contato com a bola;

Heurística: ludibriar.

Ludibriar o adversário implica em não mostrar as reais intenções de sua ação.

d) Troca de posições: ação de trocar de lugar ou espaço com companheiro de equipe.

Heurística: ganhar espaço.

Movimento, Porto Alegre, v. 20, n. 3, p. 1039-1060, jul./set. de 2014. 
A troca de posição (para espaços próximos a meta ou longe do raio de ação dos adversários) faz sentido quando há ganho de espaço efetivo.

3.3.3 AÇõES COLETIVAS DOS JOGADORES DA EQUIPE COM A POSSE DE BOLA

As ações coletivas da equipe com a posse de bola foram assim discriminadas:

a) Jogadas (gatilhos): representam uma coordenação, estabelecida previamente, das ações dos jogadores em situações de bola parada;

b) Manobras: são movimentos coordenados utilizados por uma equipe em determinadas situações (paralela, diagonal, troca ala-pivô, etc.);

c) Esquemas: representam a estrutura posicional estática da equipe pelo número de jogadores que possuem por linhas $(3: 1,2: 2$, 4:0, etc.).

Heurísticas: penetrar no sistema adversário de maneira equilibrada; mudar o ritmo, mudar a direção; balanço; profundidade; amplitude; oferecer o maior número de ações de apoio possível; tirar a bola da zona de pressão; aproximar.

Para buscar uma finalização bem-sucedida, uma equipe geralmente tem de invadir o sistema adversário. Durante essa invasão a equipe deve se manter equilibrada, buscando utilizar seu potencial ofensivo sem perder de vista o balanço defensivo.

Para que se consiga o desequilíbrio adversário, a mudança de ritmo e de direção da circulação da bola seriam fundamentais.

O balanço representaria uma ocupação equilibrada dos corredores longitudinais do campo. 
A profundidade representa a ocupação vertical do espaço de jogo, enquanto que a amplitude a ocupação horizontal.

Para ocupação inteligente do espaço, os jogadores devem ter em mente que estão agindo para oferecer apoio às ações da equipe. Quanto mais ações de apoio, maior a possibilidade de sucesso da ação da equipe.

Tirar a bola da zona de pressão significa afastar a bola da oposição direta, o que reduziria a chance de ela ser roubada, aumentaria a possibilidade da equipe organizar as suas ações futuras e, consequentemente, ser mais bem-sucedida no desequilíbrio da equipe adversária.

Aproximar adequadamente os indivíduos da equipe facilitaria a ocupação do espaço, dando segurança ao portador da bola e fechando espaços efetivos do adversário numa possível transição com a perda da bola.

\subsection{AçõES DA EQUIPE SEM A POSSE DE BOLA}

Assim como nas ações da equipe com a posse de bola, as ações da equipe sem a posse da bola foram divididas em três níveis com base no número de elementos: as ações individuais, as ações grupais (dois ou mais jogadores) e as ações coletivas.

\subsubsection{AçõES INDIVIDUAIS DOS JOGADORES DA EQUIPE SEM A POSSE DE BOLA}

As ações individuais dos jogadores da equipe sem a posse de bola foram assim discriminadas:

a) Acompanhamento: seleção de um jogador adversário para marcar e seguir neste até que a sequência da posse de bola termine ou se troque a marcação; 
Heurísticas: manter o contato com o adversário (visual, tátil, auditivo etc.); posicionar-se entre o adversário e o gol.

Para acompanhar o adversário, a manutenção do contato seja visual, tátil ou auditivo é fundamental. A manuntenção desse contato pode ser facilitada pela comunicação dos companheiros.

Posicionar-se entre o adversário e o gol implica na formação de uma barreira para a proteção da meta.

b) Abordagem: ação de aproximação ao adversário com a posse de bola;

Heurísticas: induzir para um espaço desfavorável; analisar o espaço; comunicar o espaço de abordagem e abordar o pé dominante quando perto do gol.

Como em qualquer outra ação realizada, o jogador em abordagem ao portador da bola deve buscar induzir o adversário a um espaço desfavorável.

Para que tenha mais consciência sobre a indução do adversário a análise do espaço em volta seria importante.

A comunicação por parte dos companheiros sobre o espaço a ser abordado também pode ajudar na ação. Quando o portador da bola está perto do gol, uma das estratégias para impedir uma finalização bem sucedida seria abordar o pé dominante, induzindo o adversário ao seu lado menos efetivo.

c) Interceptação: ação de impedir o passe ou finalização da equipe adversária;

Heurísticas: induzir o adversário; carrinho na trajetória.

A indução do adversário facilitaria a interceptação e recuperação da bola.

O carrinho na trajetória da bola é uma forma peculiar de interceptação em que o jogador se atira na trajetória da bola impedindo seu curso normal. 
d) Desarme: ação de roubar a bola que está em posse do adversário;

Heurísticas: manter-se equilibrado e induzir o erro.

Manter-se equilibrado e induzir o erro aumentaria a chance realizar o desarme com sucesso.

e) Movimento de equilíbrio defensivo: cobrir um espaço importante para o equilíbrio defensivo.

Heurística: analisar o espaço

Para realizar um movimento de equilíbrio, a constante análise do espaço em volta é fundamental.

3.4.2 AçõES GRUPAIS DOS JOGADORES DA EQUIPE SEM A POSSE DE BOLA

As ações grupais da equipe sem a posse de bola foram assim discriminadas:

a) Troca: ação de trocar do adversário marcado;

Heurísticas: comunicar a troca; analisar o espaço para fazer a troca.

A comunicação entre os jogadores e análise do espaço em volta aumentariam as chances de uma troca bem sucedida.

b) Cobertura: ação de apoiar o marcador do portador da bola para que este tenha segurança;

Heurísticas: comunicar o espaço de cobertura.

A comunicação entre os jogadores e análise do espaço em volta aumentariam as chances de uma cobertura bem-sucedida.

c) Dobra: ação de marcar o adversário com dois jogadores;

Heurísticas: pressionar a bola; analisar espaço; temporizar. 
A pressão ao portador da bola reduziria seu campo de ação e facilitaria a roubada de bola.

Antes de realizar a dobra, seria importante analisar o espaço em volta e selecionar o momento adequado para a dobra (temporizar), pois caso a dobra seja superada a equipe adversária ficará em situação de superioridade numérica.

d) Ajuda: ação de retorno para auxílio dos companheiros.

Heurística: voltar quando a bola passar da linha de marcação

Quando a bola estiver com os adversários e passar da linha de marcação de um jogador, este jogador pode retornar para ajudar os companheiros e aumentar a chance de recuperar a sua posse.

\subsubsection{AçõEs COLETIVAS dOS JOGAdORES DA EQUIPE SEM A POSSE DE BOLA}

As ações coletivas da equipe sem a posse de bola foram assim discriminadas:

a) Padrões: representam as formas como a equipe age sobre determinadas situações;

b) Esquemas: representam a estrutura posicional estática da equipe pelo número de jogadores que possuem por linhas $(3: 1,2: 2$, 4:0, etc.).

Heurísticas: ficar sempre que possível atrás de linha da bola; colocar pressão no portador dabola; retorno; ajuste; proporcionalidade.

O maior número possível de jogadores atrás da linha da bola aumentaria a efetividade da proteção da meta pela quantidade de obstáculos.

A imposição da pressão no portador da bola colocaria o adversário em situação de vulnerabilidade, pois reduziria seu espaço e tempo de ação e facilitaria o roubo da bola. 
O retorno representa a situação de recomposição das linhas de ação sem bola caso estejam desajustadas.

O ajuste representa a configuração equilibrada das linhas de ação sem bola.

Proporcionalidade significa manter uma distância adequada entre os companheiros de equipe com o intuito de fechar os espaços devidos (compactação).

\subsection{TRANSIÇÃO COM A RECUPERAÇÃO DA POSSE DE BOLA}

Heurísticas: reter a primeira bola; tirar a bola da zona de pressão; realizar um ataque rápido antes da reorganização da equipe adversária.

Reter a primeira bola é fundamental quando a equipe recuperou a posse da bola e está em fase de recomposição das linhas de ação com bola. Nesse caso, a perda da primeira bola poderia implicar em uma condição de desequilíbrio.

A retenção da posse da bola seria facilitada quando esta fosse retirada da zona de pressão adversária.

Ao mesmo tempo em que se busca reter a primeira bola e tirá-la da zona de pressão, a equipe pode optar por realizar um ataque rápido antes da recomposição da equipe adversária.

\subsection{TRANSIÇÃo COM A PERDA DA POSSE DE BOLA}

Heurísticas: buscar a recuperação da primeira bola; temporizar; tentar reorganizar rapidamente as linhas de ação sem bola.

Buscar a recuperação da primeira bola torna-se relevante quando se busca a recuperação imediata da posse da equipe adversária em transição desequilibrada.

A equipe que perdeu a posse de bola deve buscar temporizar as ações da equipe adversária, isto é, atrasar a ação dos adversários visando garantir o seu reequilíbrio.

Movimento, Porto Alegre, v. 20, n. 3, p. 1039-1060, jul./set. de 2014. 
A equipe que perdeu a posse de bola deve buscar recompor rapidamente suas linhas de defesa com o intuito de recuperar o equilíbrio defensivo.

\section{Considerações finais}

Mesmo com avanços importantes nas propostas de ensino das MECs (MAHLO, 1974; BAYER, 1979; BUNKER; THORPE, 1982; GRECO; 2007; GRAÇA; RICARDO; PINTO, 2006), ainda são grandes os desafios para organização dos programas de intervenção.

O presente ensaio consiste na proposição de um modelo que represente o futsal e que ajude a guiar o ensino. É importante frisar que a intenção não é criar um manual indicando passo a passo o caminho a ser seguido no processo de formação de jogadores, mas mapear e organizar conhecimentos relevantes. Dessa forma, a utilização do modelo proposto apenas faz sentido com uma apropriação crítica, o que permite ressignificações de acordo com o contexto. Partiu-se da perspectiva sistêmica com o intuito de evitar a redução do jogo à mera combinação de gestos técnicos, salientando a importância das relações na configuração de sua dinâmica e da tomada de decisão para uma ação mais eficiente.

Com efeito, é fundamental destacar a limitação de qualquer modelo para apreender a realidade e que, logicamente, o jogo de futsal é muito mais complexo do que o que foi acima apresentado. No presente trabalho buscou-se realizar um recorte da modalidade limitado somente à dimensão da eficiência e com ênfase na tomada de decisão. Outras dimensões (sociológica, psicológica, histórica, fisiológica, etc). não foram sequer mencionadas e necessitam de uma maior atenção quando da sistematização de um programa de ensino de futsal. 


The Futsal model and teaching subsidies
Abstract: The aim of this study is to propose a model for
futsal in order to help organizing its didactics. The model was
based on the authors' experience with the modality and specific
literature. A systemic approach was used in order to overcome
a technical perspective, in which action in the game is seen as
mere juxtaposing of technical gestures, and thus emphasize the
importance of decision-making.
Keywords: Sports. Teaching. Decision-support techniques.
Concept formation.

Modelo de juego del futsal y subsidios para la enseñanza
Resumen: Este estudio tiene como objetivo proponer un modelo
del juego de futsal con la intención de ayudar en la estructuración
de su enseñanza. La construcción de la representación fue
hecha con base en la experiencia de los autores y la literatura
específica. Fue adoptado un recorte sistémico a fin de superar
la perspectiva técnica, en que la acción del juego es vista como
la yuxtaposición de movimientos técnicos, y poner en relieve la
importancia de la toma de decisiones.
Palabras clave: Deportes. Técnicas de apoyo para la decisión.
Formación de concepto. Enseñanza.

\section{REFERÊNCIAS}

BAYER, C. La enseñanza de los juegos deportivos colectivos. Barcelona: Hispano Europea, 1986.

BUNKER, D; THORPE, R. A model of teaching games for secondary school. Bulletin of Physical Education, Driffield, v. 18, n. 1, p. 5-8, 1982.

GARGANTA, J. Competências no ensino e treino de jovens futebolistas. EFDeportes.com Revista Digital, Buenos Aires, v. 8, n. 45, p. 45, fev. 2002 Disponível em: < http://www.efdeportes.com/efd45/ensino.htm >. Acesso em: 21 jul. 2012.

GARGANTA, J; OLIVEIRA. Estratégia e táctica nos jogos desportivos coletivos. In: OLIVEIRA, J.; TAVARES, F. (Ed.) Estratégia e táctica nos jogos desportivos coletivos. Porto: Centro de Estudos dos Jogos Desportivos, 1996.

GARGANTA, J; GREHAIGNE J.F. Abordagem sistêmica do jogo: moda ou necessidade. Movimento, Porto Alegre , v.5, n. 10, p. 40-50, 1999.

GRAÇA, A; RICARDO, V; PINTO, D. O Ensino do Basquetebol: Aplicar o Modelo de Competência nos Jogos de Invasão Criando um Contexto Desportivo Autêntico. In: TANI, G; BENTO, J O; PETERSEN, R. D. S. Pedagogia do Desporto. Rio de

Movimento, Porto Alegre, v. 20, n. 3, p. 1039-1060, jul./set. de 2014. 
Janeiro: Guanabara Koogan, 2006. p. 299-312,.

GREHAIGNE, JF; GODBOUT, P; BOUTHIER, D. Perfomance Assesment in Team Sports. Journal of Teaching in Physical Education, Champaign, v. 16, n. 4, p.500-516, 1997.

GREHAIGNE, JF; GODBOUT, P; BOUTHIER, D. The foundations of Tatics and Strategy in Team Sports. Journal of Teaching in Physical Education, Champaign, v. 18, n.2, p.159-174, 1999.

HERNANDÉZ MORENO, J. Fundamentos del deporte: analisis de las estructuras del juego deportivo. 2. ed. Barcelona: INDE, 1998.

LAMAS, L. Modelagem estratégico-tática em esportes coletivos de invasão: aplicação ao basquetebol. 197 p. Tese (Doutorado) - Escola de Educação Física e Esporte, USP, 2012.

MAHLO, F. O Acto Tático no jogo. Lisboa: Compendium, 1974.

SEABRA, F. Identificação e análise de padrões de circulação de bola no futebol. 79 p. Dissertação (Mestrado) - Escola de Educação Física e Esporte, USP, 2010.

Endereço para correspondência:

Rafael Batista Novaes

Rua Antonio de Siqueira, 481- São Paulo-SP

CEP:08070-190

Recebido em: 25.04.2013

Aprovado em: 07.05.2014

Movimento, Porto Alegre, v. 20, n. 3, p. 1039-1060, jul./set. de 2014. 